\title{
Pitfalls in the synthesis of nanoscaled perovskite type compounds, Part I: influence of different sol-gel preparation methods and characterization of nanoscaled $\mathrm{BaTiO}_{3}$
}

\author{
H.P. Beck*, W. Eiser, R. Haberkorn \\ Department of Inorganic and Analytical Chemistry and Radiochemistry, \\ Saarland University, 66123 Saarbrücken, Germany
}

\begin{abstract}
Different sol-gel routes are compared for the synthesis of nanoscaled $\mathrm{BaTiO}_{3}$ with respect to the reaction paths and the quality of the products. The various precursor systems differ largely in their behaviour during decomposition imposing quite different procedures for their thermal treatment. It is shown that the compositional homogeneity during the process of synthesis, which is the target of solgel methods, may well be destroyed by the formation of intermediate compounds. It will only be restored after prolonged heating at higher temperatures where the crystallite sizes will in general have left the nanoregime. Due to such pitfalls the desired properties of the products with narrow size distributions will not always be ensured when working according to such recipes and the products obtained will behave quite differently in fabrication procedures like shaping and sintering of workpieces.
\end{abstract}

Keywords: $\mathrm{BaTiO}_{3}$; Perovskites; Powders-chemical preparation; Sol-gel processes

\section{Introduction}

Perovskite based materials are widely used in technical applications. Multilayer ceramic capacitors (MLCC) ${ }^{1}$, semiconductors with positive temperature coefficient of resistance $(\mathrm{PTCR})^{2,3}$ and pyroelectric detectors are some of the versatile possibilities of applications. $\mathrm{BaTiO}_{3}$ is one of the most used dielectric materials and therefore often an object of research ${ }^{4,5,6,7,8,9}$. Doped $\mathrm{BaTiO}_{3}$ and solid solutions with e.g. $\mathrm{SrTiO}_{3}$ provide new properties of ceramic materials ${ }^{10,11,12,13,14,15}$.

Modern synthesis methods like sol-gel or other precursor-routes have been intensively investigated during recent years ${ }^{16,17,18,19,20}$. Sol-gel methods give pure and nanoscaled powders in a low temperature procedure. The addition of the doping elements can be done more exactly and conveniently than in conventional solid state methods and nanoscaled 
products can be obtained. Such nanoscaled powders are of growing importance due to the miniaturisation in electrical techniques.

However, for such applications powders with well defined properties -especially in view of composition and impurity content and crystallite and/or grain size- are needed. A reproducible synthesis of such powders which come up to these needs is difficult. The single phase quality of the nanoscaled products is influenced by the synthesis route and by the precursors used. In the work reported here several known sol-gel methods ${ }^{21}$ for the synthesis of $\mathrm{BaTiO}_{3}$ were compared to show the influence of preparation on the quality of the products. The thermal decomposition of the precursors was investigated by DTA/TG and TG-MS measurements. Xray methods show the development of the crystalline phases and provide data for the determination of cell parameters, mean crystallite sizes and their distribution and structural distortions. An analysis of trace impurities in the starting materials and in the different products developing during the complex procedure was published in another paper $^{22}$.

\section{Experimental}

\section{Sol-gel acetate method}

About $17 \mathrm{~g}$ anhydrous $\mathrm{Ba}(\mathrm{OAc})_{2}$ were dissolved in $70 \mathrm{ml}$ glacial acetic-acid which was warmed up on a heating plate for complete dissolution. After cooling to room temperature this mixture was poured into a prepared solution of stoichiometric amounts of titaniumisopropoxide in $70 \mathrm{ml}$ isopropanol in a flask with inert gas atmosphere. After stirring for $1 \mathrm{~h}$ the homogenous solution was activated by slow addition of $5 \mathrm{ml}$ water followed by refluxing for $2 \mathrm{~h}$. A slight increase of the temperature initiates the gelation. The clear gel was dried at $40{ }^{\circ} \mathrm{C}$ and subsequently calcinated for $2 \mathrm{~h}$ at different temperatures in a laboratory tube furnace to obtain $\mathrm{BaTiO}_{3}$ powders.

\section{Sol-gel hydroxid method}

About $20 \mathrm{~g} \mathrm{Ba}(\mathrm{OH})_{2} \cdot 8 \mathrm{H}_{2} \mathrm{O}$ powder were dissolved by stirring and heating under reflux in a 1:1 mixture of isopropanol and glacial acetic acid. After cooling this solution to room temperature a stoichiometric amount of titaniumisopropoxide was added dropwise. After stirring a few minutes a clear solution was obtained. No addition of water is necessary due the presence of water of crystallisation in the $\mathrm{Ba}(\mathrm{OH})_{2}$ component. A slight increase of the temperature initiates the gelation. The subsequent treatments were the same as described above for the sol-gel acetate method.

\section{Sol-gel alkoxide method}

About $6 \mathrm{~g}$ Barium metal was dissolved in dry isopropanol in an inert gas atmosphere and the solution was heated under reflux to give a faint pink suspension. After cooling to room temperature a stoichiometric amount of titaniumisopropoxid was added dropwise to this mixture which was then stirred for one hour. For hydrolysis wet nitrogen was blown through the solution at room-temperature and during heating a gelation occurs. The subsequent treatment was the same as described above for the sol-gel acetate method. 


\section{Alkoxide decomposition method}

A preparation, quite similar to the sol-gel alkoxide method was used, but after the addition of titaniumisopropoxid no hydrolysis was initiated. The solvent was removed in vacuum and the residual precursor was calcinated for $2 \mathrm{~h}$ at different temperatures in air in a laboratory tube furnace to obtain $\mathrm{BaTiO}_{3}$ powders.

\section{Characterisation methods}

The DTA/TG and TG-MS measurements of the as prepared powders were performed on a STA 409 analyser (Netzsch, Germany). The precursors were put in quartz crucibles and heated in air at a rate of $5{ }^{\circ} \mathrm{C} / \mathrm{min}$ in the temperature range $20-1200^{\circ} \mathrm{C}$. A quartz crucible was also used as reference.

Density measurements were made with a microbalance (Sartorius MC1) and a He-pycnometer (Micromeritics ${ }^{\mathrm{R}}$ ) where the volume of solid material is estimated from the pressure change induced by the displacement of He gas by the solid. By such procedures also inner pores of the particles may be accessed.

Powder X-ray diffraction measurements were performed at room temperature on a D 5000 diffractometer (Siemens, Germany) operating with $\mathrm{CuK} \alpha_{1}$ radiation. The lattice parameters, the average particle size, the size distribution and the lattice distortion were determined from the X-ray data using our program FormFit ${ }^{23}$.

The lattice parameters are refined by a "whole powder pattern decomposition" procedure similar to the Rietveld method. In this program we have focussed our efforts on the development of procedures to extract information on the microstructure from XRD without the need of a Fourier transform as used in Warren-Averbach analysis. Similar to the Rietveld method, an analytical function is used to describe the whole measured X-ray pattern. Each line of the pattern is described by a split pseudo-Voigt function $(\mathrm{spV})$ with the line width $\mathrm{B}$ and the Lorentzian fraction $\eta$ and an asymmetry term $z$. which are all developed as a function of $2 \Theta$. This $\mathrm{spV}$ is itself a parametrisised convolution of three spVs representing the intensity distribution functions due to instrumental effects (instr-idf), crystallite size (size-idf) and microstrain (strain-idf). $\mathrm{LaB}_{6}$ which shows only little microstructural effects was used as standard material to determine the instr-idf.

The integral line width $\beta_{\mathrm{s}}$ of the size-idf gives a mean column height $\mathrm{L}_{\mathrm{vol}}$. Assuming spherical crystallites the mean diameter $\mathrm{D}_{\mathrm{vol}}$ can be calculated from $\mathrm{L}_{\mathrm{vol}}$. We have put up an empirical relation between the shape parameter $\eta_{D}$ of the size-idf and the variance $\sigma$ of the assumed log-normal distribution of the crystallite diameters and can therefore derive this variance accordingly. The "mean" value of microstrain $\left(\varepsilon_{0}\right)$ and additional shape depending parameters thereof will be provided by the strain-idf itself which contains them as constraining parameters. By this procedure we can derive extensive parameters of such distribution functions from our X-ray powder diagrams and not only the mean column height as most other programs do. Values derived for $D_{\text {vol }}, \sigma$ and $\varepsilon_{0}$ are given in the table. 


\section{Results and discussion}

\section{Thermoanalytical investigations}

All syntheses yield a white and agglomerated raw-powder. The TG-investigations of these samples prepared by different sol-gel methods all reveal a multiple step decomposition of the precursor (figure 1). The TG-curves of the raw-products prepared by the acetate method and by the hydroxide method are quite similar. In the first decomposition step $\left(100-200{ }^{\circ} \mathrm{C}\right)$ the excess of water and solvent disappears. At the second step $\left(200-400{ }^{\circ} \mathrm{C}\right)$ the organic compounds are burned out and the thermal decomposition of acetate occurs. The third weight loss $\left(600-750^{\circ} \mathrm{C}\right)$ results from the thermal decomposition of residual organic and carbonate components. The last weight changes occur from 750 till about $1000{ }^{\circ} \mathrm{C}$ and can be assigned to the thermal decomposition of carbonate phases.

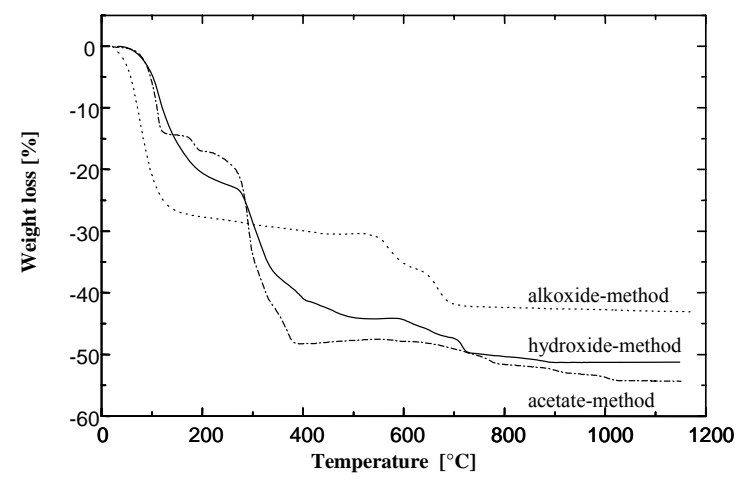

Figure 1: TG-curves of BaTi-precursors synthesised by different sol-gel methods

The TG-curve of the precursor synthesised by the alkoxide method differs in such a way that the first weight loss is larger and occurs earlier. The second step is observed at higher temperatures with a lower weight loss and it is closely followed by the third. Above $700{ }^{\circ} \mathrm{C}$ no further weight-changes were detected. The main difference in these methods is that the alkoxide method contains no acetic acid or acetate compounds. Therefore the generation of carbonates is not favoured, since the main source for the carbonate phase is the thermal decomposition of acetate compounds. This can be followed by the detection of aceton, which is a known product of the thermal decomposition of acetate compounds, by mass spectrometry.

\section{X-ray investigations}

The thermal decomposition can also be illustrated by X-ray diffraction measurements (figures 2 - 4). The raw-powders contain mainly amorphous or unknown crystalline phases. The first crystalline perovskite-phases are generated after a heating treatment at $400{ }^{\circ} \mathrm{C}$. The synthesis methods influence the generation of the crystalline perovskite-phases in a particular way. In the X-ray scans, given in figure 2, it can be seen that the product of the acetate method yields a carbonate-phase at $400{ }^{\circ} \mathrm{C}$, the hydroxide- and the sol-gel-alkoxide method, however, give amorphous phases under such conditions. The alkoxide decomposition method yields 
crystalline perovskite-phases and only small amounts of carbonate at this relatively low temperature.

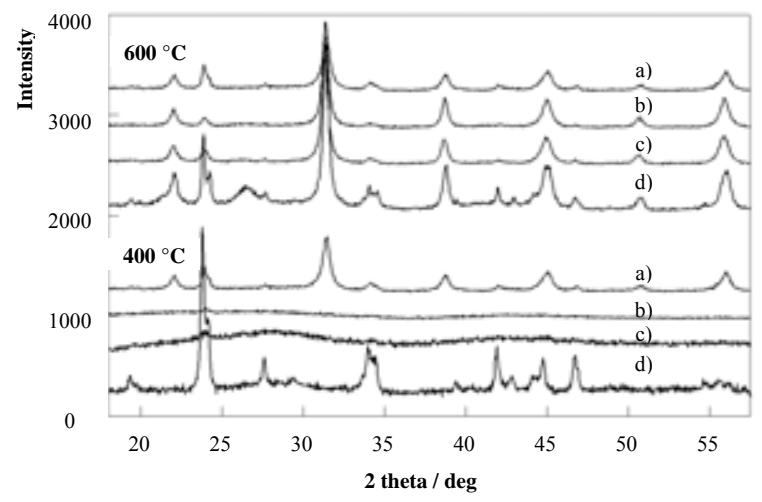

Figure 2: X-ray diffractograms of BaTi-samples calcinated at 400 and $600{ }^{\circ} \mathrm{C}$ respectively and synthesised by different methods: a) decomposition-method, b) alkoxide-method, c) hydroxide-method, d) acetate-method.

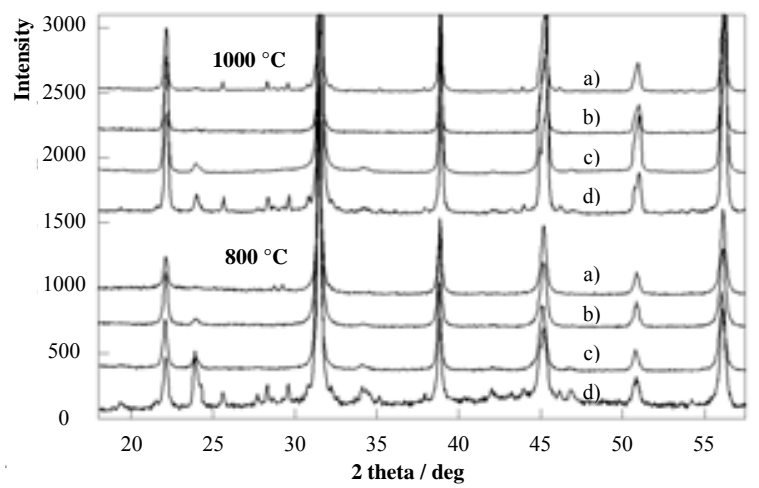

Figure 3: X-ray diffractograms of BaTi-samples calcinated at 800 and $1000{ }^{\circ} \mathrm{C}$ respectively and synthesised by different methods: a) decomposition-method, b) alkoxide-method, c) hydroxide-method, d) acetate-method.

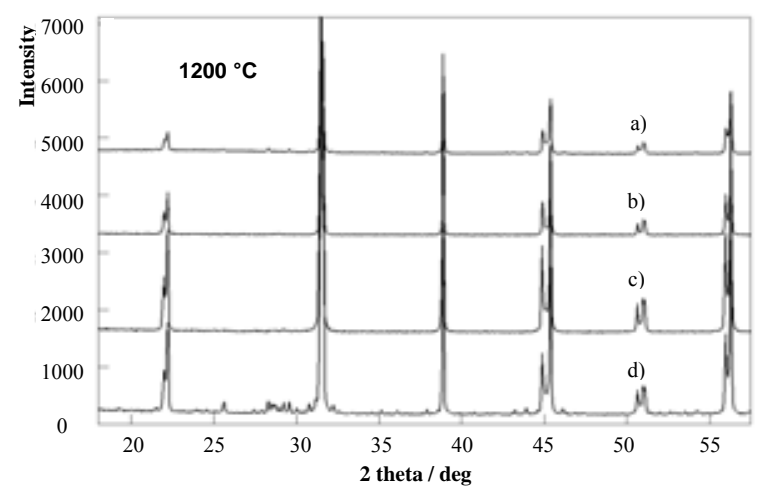

Figure 4: X-ray diffractograms of BaTi-samples calcinated at $1200{ }^{\circ} \mathrm{C}$ and synthesised by different methods: a) decomposition-method, b) alkoxide-method, c) hydroxide-method, d) acetate-method.

In the temperature region from 500 to $600{ }^{\circ} \mathrm{C}$ all precursors yield the crystalline perovskite product. As expected the product synthesised by the acetate method shows the most carbonate. After heating at higher temperatures the crystallinity of the products is improved 
giving sharper reflections, a splitting of the peaks occurs and the carbonate-phase disappears (figure 3). The more carbonate is present at lower temperature the more is left also at higher temperatures and this leads to additional formation of new Ba-Ti phases under such conditions by reaction with the unused Ti-O matrix. Therefore only the powders prepared by the alkoxide method contain no foreign phase after treatment at $1000^{\circ} \mathrm{C}$. At $1200^{\circ} \mathrm{C}$ all products except those obtained by the acetate method are pure perovskite phases.

The formation of carbonate phases beside the target product therefore depends on the choice of the synthesis route. For reasons of stoichiometry the formation of certain amounts of $\mathrm{BaCO} 3$ should be accompanied by Ti-rich compounds. This will lead to a segregation of the formerly homogeneous system into $\mathrm{Ba}$ - and Ti-rich regions. On heating $\mathrm{BaCO}_{3}$ reacts under evolution of $\mathrm{CO}_{2}$ with the Ti-rich compounds to form $\mathrm{BaTiO}_{3}$ and other Ba-Ti-Oxide phases like $\mathrm{Ba}_{2} \mathrm{TiO}_{4}$ and with the $\mathrm{TiO}_{2}$-rich particles to give $\mathrm{BaTi}_{2} \mathrm{O}_{5}$.

The formation of this portion of $\mathrm{BaTiO}_{3}$ from $\mathrm{BaCO}_{3}$ and $\mathrm{TiO}_{2}$ and by compositional equilibration of the other ternary compounds occurs later and at higher temperatures. The perovskite product produced earlier has a good crystallinity at this time and the crystal growth has proceeded whereas the new product only begins to form and therefore still has smaller crystallite sizes. In the end this will lead to a broader - perhaps even bimodal - distribution of the crystallite sizes. The evolution of all the steps mentioned is depicted in scheme 1 .

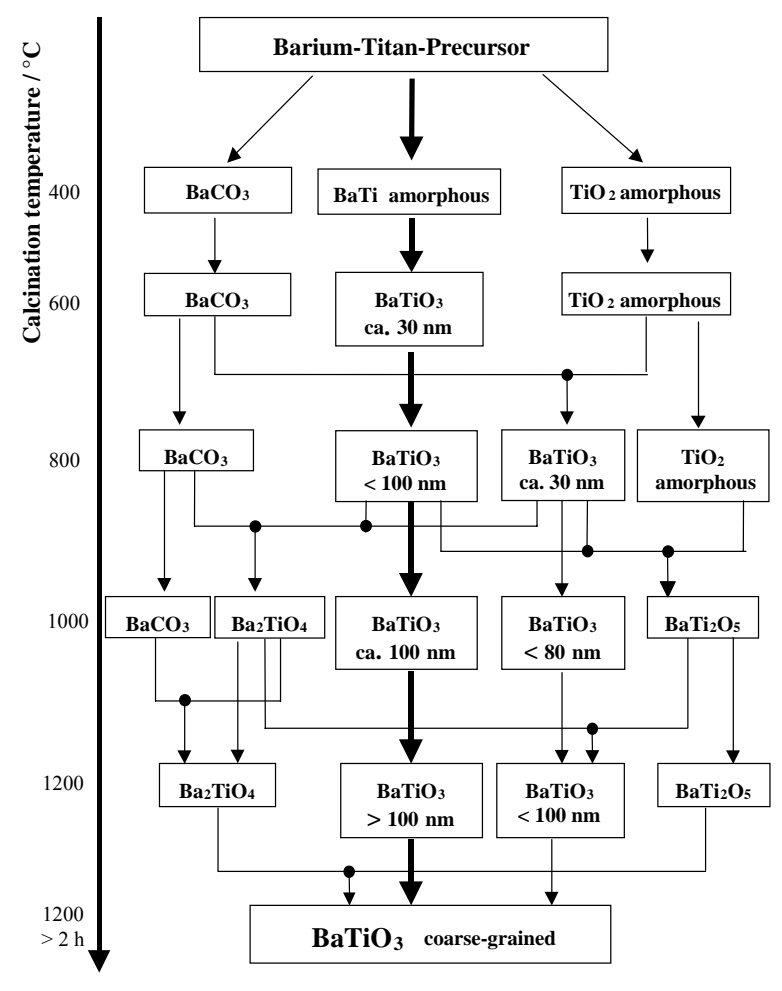

Scheme 1: Formation of $\mathrm{BaTiO}_{3}$ from the precursors and possible developments of further phases in the presence of $\mathrm{BaCO}_{3}$.

In order to investigate the effect of varying stoichiometry in the precursor system closer we have performed a series of experiments using the hydroxide method and varying the stoichiometric relation of $\mathrm{Ba} / \mathrm{Ti}$ from $2: 1$ to $1: 2$. The X-ray series taken for different compositions after various temperature treatments differ considerably. A precursor with 2:1 composition shows reflections already at room temperature, at $400{ }^{\circ} \mathrm{C} \mathrm{BaCO}_{3}$ has formed and 
at $600{ }^{\circ} \mathrm{C} \mathrm{BaTiO}_{3}$ also appears as by-product. Beginning from $800{ }^{\circ} \mathrm{C} \mathrm{Ba}_{2} \mathrm{TiO}_{4}$ is formed and at temperatures above $1000{ }^{\circ} \mathrm{C}$ this is the only phase left. In systems with high Ti content there is a considerable background noise in the diffractograms due to amorphous phases. A precursor with a $1: 2$ composition shows no crystalline phase up to $600{ }^{\circ} \mathrm{C}$. Later on $\mathrm{BaCO}_{3}$ begins to form. It is only after a treatment at $800{ }^{\circ} \mathrm{C}$ that reflections of $\mathrm{BaTi}_{2} \mathrm{O}_{5}$ appear.

After heating at $1200{ }^{\circ} \mathrm{C}$ very low contents of $\mathrm{BaTiO}_{3}$ may sometimes be discerned by close inspection of the base line besides the main product $\mathrm{BaTi}_{2} \mathrm{O}_{5}$. These observations may again demonstrate how reaction pathways can change by variations in stoichiometry.

\section{Structural parameters}

\begin{tabular}{|c|c|c|c|c|c|c|c|}
\hline & $\begin{array}{c}\text { Calcination- } \\
\text { temperature } \\
{\left[{ }^{\circ} \mathrm{C}\right]}\end{array}$ & $\begin{array}{l}\text { Lattice } \\
\text { a (cubic) } \\
{[\mathrm{pm}]}\end{array}$ & $\begin{array}{l}\text { arameter } \\
\text { a (tetr.) } \\
{[\mathrm{pr}}\end{array}$ & $\begin{array}{l}\text { c (tetr.) } \\
\text { n] }\end{array}$ & $\begin{array}{c}\text { Crystallite size } \\
\left\langle\mathbf{D}_{\mathrm{vol}}>\right. \\
{[\mathrm{nm}]}\end{array}$ & $\begin{array}{c}\text { Microstrain } \\
\varepsilon \\
{[\%]}\end{array}$ & $\begin{array}{c}\text { Variance* }^{*} \\
\sigma\end{array}$ \\
\hline $\begin{array}{l}\mathrm{BaTiO}_{3} \\
\text { Hydroxide- } \\
\text { Method }\end{array}$ & $\begin{array}{c}600 \\
800 \\
1000 \\
1200\end{array}$ & $400.20(2)$ & $\begin{array}{l}400.22(2) \\
399.53(1) \\
399.29(1)\end{array}$ & $\begin{array}{l}401.23(1) \\
402.83(1) \\
403.39(1)\end{array}$ & $\begin{array}{c}41.8(15) \\
64.28(9) \\
120.7(11) \\
525(40)\end{array}$ & $\begin{array}{c}0.436(9) \\
0.152(3) \\
0,05 \\
0.029(1)\end{array}$ & $\begin{array}{l}1.62 \\
1.46 \\
1.14 \\
1.14\end{array}$ \\
\hline $\begin{array}{l}\mathrm{BaTiO}_{3} \\
\text { Acetate- } \\
\text { Method }\end{array}$ & $\begin{array}{c}600 \\
800 \\
1000 \\
1200\end{array}$ & $401.37(3)$ & $\begin{array}{l}400.03(2) \\
399.66(1) \\
399.39(1)\end{array}$ & $\begin{array}{l}401.25(1) \\
402.81(1) \\
403.39(1)\end{array}$ & $\begin{array}{c}33.0(10) \\
70.0(11) \\
114.3(28) \\
217(5)\end{array}$ & $\begin{array}{c}0.370(13) \\
0.5 \\
0.3 \\
0.1\end{array}$ & $\begin{array}{l}1.68 \\
1.46 \\
1.29 \\
1.14\end{array}$ \\
\hline $\begin{array}{l}\mathrm{BaTiO}_{3} \\
\text { Alkoxide- } \\
\text { Method }\end{array}$ & $\begin{array}{c}600 \\
800 \\
1000\end{array}$ & $401.71(3)$ & $\begin{array}{l}400.16(1) \\
399.48(1)\end{array}$ & $\begin{array}{l}401.78(1) \\
402.17(1)\end{array}$ & $\begin{array}{c}40.6(12) \\
53.6(14) \\
362(8)\end{array}$ & $\begin{array}{l}0.455(6) \\
0.186(3) \\
0.123(1)\end{array}$ & $\begin{array}{l}1.34 \\
1.89 \\
1.14\end{array}$ \\
\hline $\begin{array}{l}\mathrm{BaTiO}_{3} \\
\text { Alkoxide } \\
\text { Decomposi- } \\
\text { tion- } \\
\text { Method }\end{array}$ & $\begin{array}{c}400 \\
500 \\
550 \\
600 \\
650 \\
700 \\
800 \\
900 \\
1000 \\
1280 \\
\end{array}$ & $\begin{array}{l}401.27(3) \\
400.97(3) \\
400.84(3) \\
400.86(2) \\
400.87(2) \\
400.61(1)\end{array}$ & $\begin{array}{l}400.35(2) \\
400.13(1) \\
399.62(1) \\
399.31(1)\end{array}$ & $\begin{array}{l}401.52(1) \\
401.69(2) \\
402.45(1) \\
402.82(2)\end{array}$ & $\begin{array}{c}19.5(23) \\
23.8(29) \\
30.9(19) \\
30.6(21) \\
27.6(26) \\
37.1(16) \\
48(2) \\
645(14) \\
106.9(30) \\
183(10) \\
\end{array}$ & $\begin{array}{l}0.271(2) \\
0.213(5) \\
0.213(3) \\
0.177(8) \\
0.243(2) \\
0.196(4) \\
0.146(7) \\
0.148(2) \\
0.090(1) \\
0.063(1)\end{array}$ & $\begin{array}{l}2.16 \\
2.03 \\
1.92 \\
1.95 \\
1.74 \\
1.87 \\
1.98 \\
1.92 \\
1.57 \\
1.14\end{array}$ \\
\hline
\end{tabular}

Table 1: The standard deviations given in brackets are the result of the least squares refinement procedure. Values given without deviations have been fixed during the refinement.

* $\sigma$ is the variance of the normal distribution giving a measure for the width of the distribution. Its standard deviation is \pm 0.1 .

The results of the evaluation of X-ray data by the software FormFit ${ }^{23}$ are listed in table 1 . The standard deviations given there are the result of a mathematical procedure (least squares fit) and should be assessed accordingly. In all cases the c/a-ratios increase with the calcination temperature (figure 5) as do the crystallite-sizes (figure 6). It can clearly be seen that the degree of tetragonality depends on the crystallite size. It is known in literature ${ }^{10}$ that below a critical crystallite size of $30-50 \mathrm{~nm}$ only a cubic structure is present. The influence of the 
synthesis route on mean crystallite sizes is also remarkable (figure 6). The crystallite growth of powders prepared by the alkoxide method is faster than that prepared by the other two. The products of the hydroxide method also have a slightly higher growth rate above $1000{ }^{\circ} \mathrm{C}$.

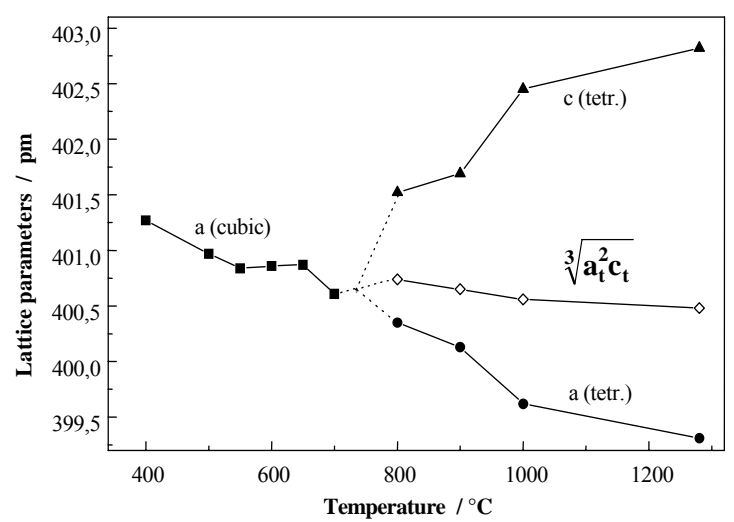

Figure 5: Lattice parameters of $\mathrm{BaTiO}_{3}$ synthesised by the decomposition method versus calcination temperature.

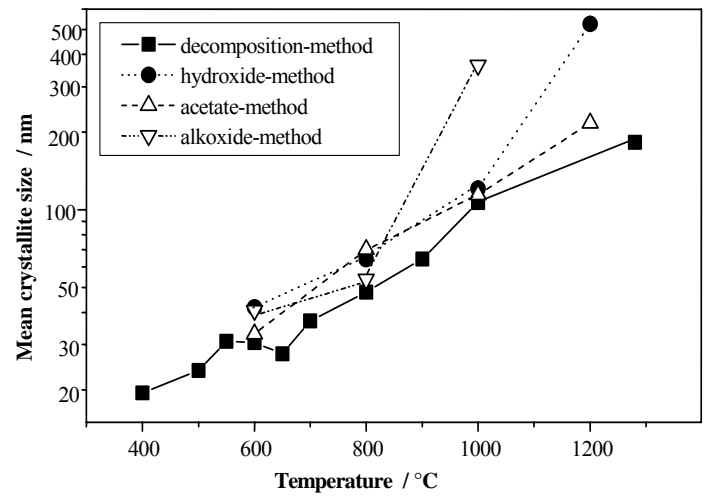

Figure 6: Mean crystallite size of $\mathrm{BaTiO}_{3}$ synthesised by different methods versus calcination temperature.

One of the most interesting parameters given in table 1 is " $\sigma$ " by which we mean the variance of the size distribution, i. e. the width of the spread of the crystallite size when its distribution is described as a log-normal one. The evolution of these parameters gives a good insight into the formation and growth of the crystallites. The $\sigma$ values for products obtained by the hydroxide- and acetate method treated at 600 and $800{ }^{\circ} \mathrm{C}$ are quite similar, they differ for the $1000{ }^{\circ} \mathrm{C}$ treatment. (A value of 1.14 is a boundary case in the frame of the specific mathematical evaluation used in our FormFit-program ${ }^{23}$, and it means that the size distribution is very narrow, so a further refinement of this parameter makes no sense.) For the acetate method the value after treatment at $1000^{\circ} \mathrm{C}$ is larger, and this is consistent with the arguments given above. At this temperature new and at first nano-crystalline $\mathrm{BaTiO}_{3}$ appears in addition to the product formed already at lower temperatures which has undergone a longer history of crystallite growth. As stated above the distribution may now even be bimodal, but we have no algorithm at present when using our full pattern profile evaluation to derive such a situation from the data. However, the larger $\sigma$ value is also an indication for it. 
The final value for the products of the alkoxide method is again the same, but we see that the size distribution has expanded considerably at medium temperatures. The first crystallites formed at $600{ }^{\circ} \mathrm{C}$ have about the same size as for the hydroxide- and acetate method. However, at $800{ }^{\circ} \mathrm{C}$ a different combined process of formation and growth is evidently taking place, a few crystallites start growing strongly fed by the amorphous alkoxide matrix while others are newly formed by completely different processes. At $1000{ }^{\circ} \mathrm{C}$ the situation has changed. It may be conjectured that the amorphous matrix is now used up and that crystallite growth proceeds via a conventional Ostwald ripening process.

The alkoxide decomposition method is again quite different. The spread of the crystallite sizes is very large from the beginning on, and it is comparable to the other ones only after a longer treatment at very high temperatures when crystallite sizes start to leave the nano-regime.

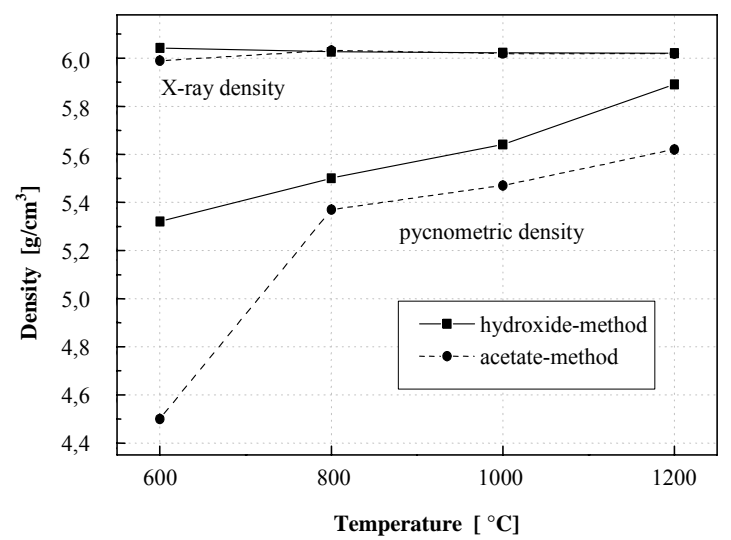

Figure 7: X-ray and pycnometric density of $\mathrm{BaTiO}_{3}$ prepared by different routes

The microstrain parameter $\varepsilon$ is another feature which differs considerably in the different routes. One would expect this parameter to decrease on treatment at higher temperatures and in most cases it does. Structural imperfections in products of the hydroxide and the alkoxide method can easily be annealed. In the case of the alkoxide decomposition method there is a slow decrease only but beginning from quite low values. The acetate method is again quite different. The microstrain at first even increases when going to higher temperatures and there remains a considerable width of distribution of this parameter making refinements quite difficult. It is only after treatment at $1200{ }^{\circ} \mathrm{C}$ that $\varepsilon$ attains normal values. Differences in crystallite growth and agglomeration are also reflected in the development of the densities of the powders as measured by He-pycnometry. Figure 7 shows that the products of the acetate method have distinctly lower densities than those of the hydroxide method. In general the densities will be different due to the different mechanisms of crystal formation giving more or less defects. Moreover, during the stages of the thermal treatment of the precursor systems the different reactions taking place will produce more or less gaseous products and this will in addition influence the porosity within and around the primary particles as well as that of the growing grains. Due to these differences in density and porosity the products obtained by these processes will behave quite differently during sintering to ceramic bodies. 


\section{Conclusion}

The work presented here compares different sol-gel routes for the synthesis of nanoscaled $\mathrm{BaTiO}_{3}$ with respect to the reaction paths and the quality of the products. The various precursor systems show quite large differences in their behaviour during thermal decomposition. Weight loss curves and intermediately existing amorphous and/or crystalline phases may differ considerably and this imposes quite different procedures for the thermal treatment of the precursors. It could be shown that the compositional homogeneity during the process of synthesis which is aimed at when using sol-gel methods may well be destroyed by the formation of intermediate compounds. Carbonate phases formed especially in the case of the acetate method will in a way change the local composition and stimulate the formation of Ti-rich compounds. The compositional homogeneity will only be restored after prolonged treatment at higher temperatures, however, under such conditions the crystallite sizes will also have considerably increased. It could also be shown that the width of the size distribution of the crystallites depends very much on the different routes. Due to such pitfalls the desired nanocrystalline property of the products with narrow size distributions is therefore not always ensured when working according to such recipes. A comparison of microstrain and density parameters indicates that these materials will behave quite differently in fabrication procedures like shaping and sintering of workpieces.

\section{References}

[1] S. Schalg, H.F. Eicke, Size driven Phase Transition in Nanocrystalline $\mathrm{BaTiO}_{3}$, Solid State Communications, 1994, 91, 883-887

[2] H.A. Sauer, J.R. Fisher, Processing of Positive Temperature Coefficient Thermistors, Journal of the American Ceramic Society 1960, 43, 297-301

[3] W. Heywang, Semiconducting Barium Titanate, Journal of Materials Science, 1971, 6, 1214-1226

[4] R.P.S. Lobo; Nelcy D. S. Mohallem; L. Moreira, Grain-Size Effects on Diffuse Phase Transition of Sol-Gel Prepared Barium Titanate Ceramics, Journal of the American Ceramic Society 1995, 78, 1343-1346

[5] A. Mosset, I. Gautier-Luneau, J. Galy, Sol-Gel Processed $\mathrm{BaTiO}_{3}$ : Structural Evolution from the Gel to the Crystallisation Powder, Journal of Non-Crystalline Solids, 1988, 100, 339-344

[6] B. Samuneva, S. Jambazov, D. Lepkova, Y. Dimitriev, Sol-Gel Synthesis of $\mathrm{BaTiO}_{3}$ and $\mathrm{Ba}_{1-\mathrm{x}-\mathrm{y}} \mathrm{Ca}_{\mathrm{y}} \mathrm{Sr}_{\mathrm{x}}\left(\mathrm{ZryTi}_{1-\mathrm{y}}\right) \mathrm{O}_{3}$ Perovskite Powders, Ceramics International, 1990, 16, $355-360$

[7] M. A. Delfrate, M. Leoni, L. Nanni, E. Melioli, B.E. Watts, F. Leccabue, Electrical Characterisation of $\mathrm{BaTiO}_{3}$ made by Hydrothermal Methods, Journal of Materials Science; Materials in Electronics, 1994, 5, 153-156

[8] L. Benguigui, Electrical Phenomena in Barium Titanate Ceramics, Journal of Physical Chemistry of Solids, 1973, 34, 573-581

[9] H.C. Graham, N.M. Tallan, K.S. Mazdiyasni, Electrical Properties of High-Purity Polycrystalline Barium Titanate, Journal of the American Ceramic Society, 1971, 54, 548-553 
[10] J.M. Wilson, Mineral Review: Barium Titanate, American Ceramic Society Bulletin, 1995, 74, 106-108

[11] A.C. Caballero, J.F. Fernandez, C. Moure, P. Duran, ZnO-doped $\mathrm{BaTiO}_{3}$ : Microstructure and Electrical Properties, Journal of the European Ceramic Society, 1997, 17, 513-523

[12] Y. Goto, S. Kachi, Studies on the Mechanism of Electric Conduction in Fe-doped $\mathrm{BaTiO}_{3}$ Single Crystals, Journal of Physical Chemistry of Solids, 1971, 32, 889-895

[13] T. Matsuoka, Y. Matsuo, H. Sasaki, S. Hayakawa, PTCR Behavior of $\mathrm{BaTiO}_{3}$ with $\mathrm{Nb}_{2} \mathrm{O}_{5}$ and $\mathrm{MnO}_{2}$ Additives, Journal of the American Ceramic Society, 1972, 55, 108

[14] J. Karch, R. Birringer, H. Gleiter, Ceramics Ductile at Low Temperature, Nature, 1987, 330, 556-558

[15] A.G. Belous, O.I.V'yunov, B.S. Khomenko, Microstructure and Semiconducting Properties of Barium Titanate Containing Heterovalent Substituents on the Titanium site, Inorganic Materials, 1989, 34, 725-729

[16] Hirokazu Shimooka, Preparation of Dense $\mathrm{BaTiO}_{3}$ Ceramics from Sol-Gel-Derived Monolithic Gels, Journal of the American Ceramic Society, 1995, 78, 2849-2852

[17] P. Nanni, M. Leoni, V. Buscaglia, G. Aliprandi, Low-Temperature Aqueous Preparation of Barium Metatitanate Powders, Journal of the European Ceramic Society, 1994, 14, 85-90

[18] H.S. Potdar, P. Singh, S.B. Deshpande, P.D. Godbole, S.K. Date, Low-temperature Synthesis of Ultrafine Barium Titanate $\left(\mathrm{BaTiO}_{3}\right)$ using Organometallic Barium, Materials Letters, 1990, 10, 112-117

[19] D. Hennings, W. Mayr, Thermal Decomposition of (BaTi) Citrates into Barium Titanate, Journal of Solid State Chemistry, 1978, 26, 329-338

[20] V.A. Vasiljev, K.A. Vorotilov, M.I. Yanovskaya, L.I. Solovjeva, A.S. Sigov, Sol-Gel Derived Barium-Strontium Titanate Films, Journal of Sol-Gel Science and Technology, 1998, 13, 877-883

[21] H.P. Beck, F. Müller, R. Haberkorn, D. Wilhelm, Synthesis of Perovskite Type Compounds via Different Routes and their X-ray Characterisation, Nanostructured Materials, 1995, 6, 659-662

[22] W. Eiser, H.P. Beck, Trace Analysis of Impurities in Sol-Gel Prepared $\mathrm{BaTiO}_{3}$ Powders with ICP-MS, Fresenius Journal of Analytical Chemistry, 1999, 364, $417-$ 421

[23] C.E. Krill, R. Haberkorn, R. Birringer, Specification of Microstructure and Characterization by Scattering Techniques, Handbook of Nanostructured Materials and Nanotechnology, 2000, 2, 155-211 